\title{
A Novel Cellular Handset Design for an Enhanced Antenna Performance and a Reduced SAR in the Human Head
}

\author{
Salah I. Al-Mously ${ }^{1,2}$ and Marai M. Abousetta ${ }^{1,2}$ \\ ${ }^{1}$ Department of Electrical and Electronics Engineering, School of Applied Sciences and Engineering, \\ Academy of Graduate Studies, P.O. Box 79031, Janzoor, Tripoli, Libya \\ ${ }^{2}$ Department of Microwave and Radar Engineering, The Higher Institute of Electronics, P.O. Box 38645, \\ Beni-Walid, Libya \\ Correspondence should be addressed to Salah I. Al-Mously, salah.mously@hieb.edu.ly
}

Received 17 November 2007; Accepted 21 March 2008

Recommended by Seong-Youp Suh

\begin{abstract}
This paper presents a novel cellular handset design with a bottom-mounted short loaded-whip antenna. This new handset design is modeled and simulated using a finite difference time-domain (FDTD)-based platform SEMCAD. The proposed handset is based on a current commercially available bar-phone type with a curvature shape, keypad positioned above the screen, and top-mounted antenna. The specific absorption rates (SARs) are determined computationally in the specific anthropomorphic mannequin (SAM) and anatomically correct model of a human head when exposed to the EM-field radiation of the proposed cellular handset and the handset with top-mounted antenna. The two cellular handsets are simulated to operate at both GSM standards, $900 \mathrm{MHz}$ as well as $1800 \mathrm{MHz}$, having different antenna dimensions and intput power of $0.6 \mathrm{~W}$ and $0.125 \mathrm{~W}$, respectively. The proposed human hand holding the two handset models is a semirealistic hand model consists of three tissues: skin, muscle, and bone. The simulations are conducted with handset positions based on the IEEE standard 1528-2003. The results show that the proposed handset has a significant improvement of antenna efficiency when it is hand-held close to head, as compared with the handset of top-mounted antenna. Also, the results show that a significant reduction of the induced SAR in the human head-tissues can be achieved with the proposed handset.
\end{abstract}

Copyright (c) 2008 S. I. Al-Mously and M. M. Abousetta. This is an open access article distributed under the Creative Commons Attribution License, which permits unrestricted use, distribution, and reproduction in any medium, provided the original work is properly cited.

\section{INTRODUCTION}

Due to enormous increase in the number of cellular handset users around the world, many questions are raised about the possible hazard effect of the cellular handset electromagnetic field (EMF) radiation. Thereby, health concerns regarding the use of a cellular handset near the human head have been growing and took a lot of attention by researchers.

The interaction of the cellular handset with the human head has been investigated by many published papers with considering; first, the effect of the human head on the handset antenna performance, including the feed-point impedance, gain, and efficiency [1-4], second, the impact of the antenna EM radiation on the user's head due to the absorbed power, which is measured by predicting the induced specific absorption rate (SAR) in head tissues $[5,6]$.

The protocol and procedures for the measurement of the peak spatial-average SAR induced inside a simplified head model of the cellular handset users are specified by
IEEE Standard-1528 [7] and IEC 62209-1 [8]. Both standards specified the specific anthropomorphic mannequin (SAM) as a simplified physical model (phantom) of the human head. This SAM has also been adopted by many committees, associations, and commissions [9-11]. The SAM has been developed by the IEEE Standards Coordinating Committee 34, Subcommittee 2, Working Group 1 (SCC34/SC2/WG1) as a lossless plastic shell, filled with a homogeneous liquid, and a thin lossless ear spacer, whereas (SCC34/SC2/WG2) has suggested the same SAM but with different plastic shell parameters [5].

Anatomically correct models of a nonhomogeneous human head at different ages were used to evaluate the performance of the handset on a human-head phantom $[5,12,13]$. In this paper, a nonhomogeneous high-resolution numerical correct model of a European female head [14], available with SPEAGE-Schmidt \& Partner Engineering AG [15], is used. 
Handset models with a keypad positioned above the screen are available commercially. Linux released a more comfortable of such a handset with a top-mounted external antenna and a curvature shape [16]. This new design ensures that much of the handset rests in the palm of the hand, thus, improving support and control. In addition to the improved grip, the thumb rests in a comfortable position directly above the buttons of the keypad. The improved angle for the thumb makes it unnecessary to shift the handset around in the hand while typing text [16].

In this paper, the proposed handset design with a bottom-mounted antenna is based on the handset model in [16]. An FDTD-based platform SEMCAD [15] is used for simulation. The Antenna performance is evaluated for both handset models in free space, hand-held, and hand-held close to head. A semirealistic hand model consists of three tissues is designed to simulate the human hand. The induced SAR's in head models are evaluated at GSM standards, $900 \mathrm{MHz}$ and $1800 \mathrm{MHz}$, with antenna intput power of $0.6 \mathrm{~W}$ and $0.125 \mathrm{~W}$, respectively. Handset positions, cheek and tilt $\left(15^{\circ}\right)$, with respect to head are adopted according to IEEE standard 1528 [7].

\section{CELLULAR HANDSET DESIGN AND FDTD SIMULATION}

\subsection{Handset structure}

The handset model in [16] (will be referred later as model no. 1) is simulated using an FDTD-based platform SEMCAD (Simulation Platform for Electromagnetic Compatibility, Antenna Design and Dosimetry) ver. 12 JUNGFRAU [15]. The proposed handset with a bottom-mounted antenna (will be referred later as model no. 2) is also designed and simulated, where most handset components, such as PCB, LCD, Battery, and keypad, are considered in the design simulation. These components are not located identically in both handset models due to different antenna positions. Both models are simulated to operate at $900 \mathrm{MHz}$ as well as $1800 \mathrm{MHz}$.

Figure 1(a) shows the physical model of the handset released by Linux [16], whereas Figure 1(b) exhibits the proposed physical model with bottom-mounted antenna. Figure 2 shows the numerical equivalent of both physical models used for the FDTD simulation. The maximum dimensions of both handsets are set to $45 \times 16 \times 130 \mathrm{~mm}$ with a PCB symmetrically embedded inside the housing. The acoustic output position is set according to IEEE standard 1528 [7]. Figure 3 shows the numerical components structure of the handset models. The dielectric parameters of handset materials given in [6] are used.

\subsection{Antenna design and specifications}

Instead of using a helical antenna, a short-whip antenna top loaded with a small cylinder [17] is suggested for both designs of models as depicted in Figure 4 . Table 1 shows the physical and electrical antenna specifications that optimized at both GSM standards for both handset models.

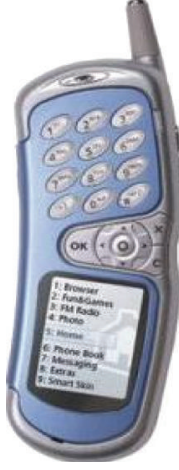

(a)

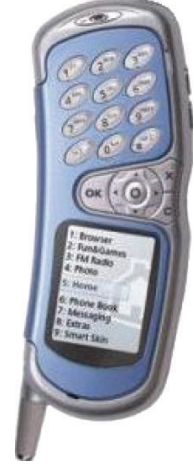

(b)
FIGURE 1: The physical model of (a) the handset released by Linux, and (b) the proposed handset with bottom-mounted antenna.

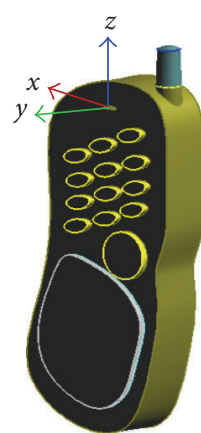

(a)

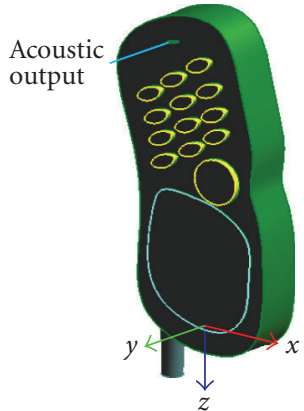

(b)
Figure 2: The CAD representation of both handset models.

\section{GRID GENERATION AND SIMULATION FACTORS SETTING}

\subsection{Cellular handset in free-space}

To align the simulated handset components to the FDTD grid accurately, a minimum spatial resolution of $0.1 \times 0.1 \times$ $0.1 \mathrm{~mm}^{3}$ and maximum spatial resolution of $5 \times 5 \times 5 \mathrm{~mm}^{3}$ in the $x, y$, and $z$ directions are chosen with grading ratio of 1.2. For the handset model no. 1, the mesh cells amounts are 4.58979 Mcells and 3.95494 Mcells, at $900 \mathrm{MHz}$ and $1800 \mathrm{MHz}$, respectively, whereas for the model no. 2, the mesh cells amounts are 6.82675 Mcells and 4.89154 Mcells, at $900 \mathrm{MHz}$ and $1800 \mathrm{MHz}$, respectively.

\subsection{Cellular handset in hand}

A semirealistic human-hand model consists of three tissues: skin, muscle, and bone, are designed using SEMCAD [15] to simulate both handset models in hand, as shown in Figure 5. The FDTD grid has a minimum spatial resolution of $0.5 \times 0.5 \times 0.5 \mathrm{~mm}^{3}$ and maximum spatial resolution of $10 \times 10 \times 10 \mathrm{~mm}^{3}$ in the $x, y$, and $z$ directions, with grading ratio of 1.2. For the hand-held of model no. 1, the mesh cells amounts are 4.58979 Mcells and 3.95494 Mcells, at $900 \mathrm{MHz}$ and $1800 \mathrm{MHz}$, respectively, whereas for the hand-held of 


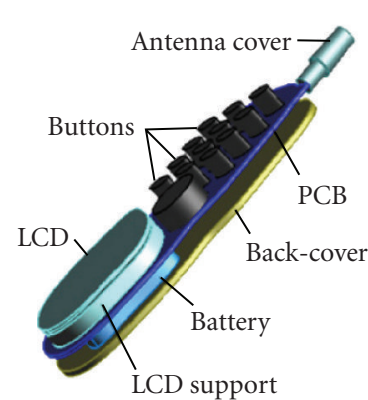

(a)
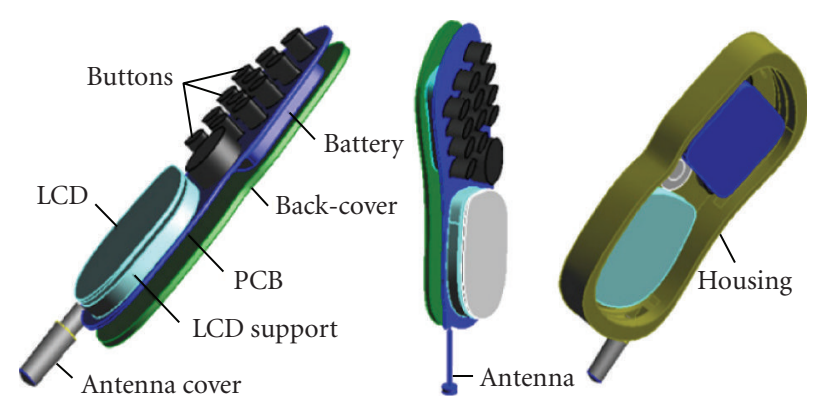

(b)

FIGURE 3: Numerical components structure of (a) the handset model no. 1, and (b) the proposed handset model no. 2.

TABLE 1: The proposed antenna dimensions and specifications for both handset design models at different frequencies.

\begin{tabular}{|c|c|c|c|c|c|c|}
\hline \multicolumn{7}{|c|}{ Model no. 1} \\
\hline Frequency & Matching lumped element & $L_{1}$ & $D_{1}$ & $L_{2}$ & $D_{2}$ & Impedance in ohm \\
\hline $900 \mathrm{MHz}$ & $29.65 \mathrm{nH}$ & $19 \mathrm{~mm}$ & $1 \mathrm{~mm}$ & $2 \mathrm{~mm}$ & $6 \mathrm{~mm}$ & $46.4+j 0.0$ \\
\hline $1800 \mathrm{MHz}$ & No matching needed & $18 \mathrm{~mm}$ & $1 \mathrm{~mm}$ & $2 \mathrm{~mm}$ & $6 \mathrm{~mm}$ & $47.3-j 0.016$ \\
\hline \multicolumn{7}{|c|}{ Model no. 2} \\
\hline Frequency & Matching lumped element & $L_{1}$ & $D_{1}$ & $L_{2}$ & $D_{2}$ & Impedance in ohm \\
\hline $900 \mathrm{MHz}$ & $25.24 \mathrm{nH}$ & $23 \mathrm{~mm}$ & $1 \mathrm{~mm}$ & $2 \mathrm{~mm}$ & $6 \mathrm{~mm}$ & $42.2+j 0.0$ \\
\hline $1800 \mathrm{MHz}$ & No matching needed & $22 \mathrm{~mm}$ & $1 \mathrm{~mm}$ & $2 \mathrm{~mm}$ & $6 \mathrm{~mm}$ & $47.9-j 0.001$ \\
\hline
\end{tabular}

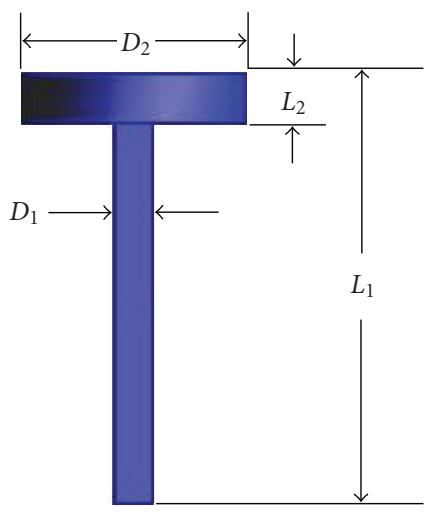

FIgURE 4: The proposed loaded short-whip antenna with dimensions.

model no. 2, the mesh cells amounts are 6.82675 Mcells and 4.89154 Mcells, at $900 \mathrm{MHz}$ and $1800 \mathrm{MHz}$, respectively.

\subsection{Cellular handset in hand close to head}

As defined in IEEE standard 1528-2003 [7], two handset positions are considered in presence of human-head, cheek and tilt $\left(15^{\circ}\right)$. The head is simulated using both, homogeneous and nonhomogeneous phantoms.

The homogeneous head model is a SAM phantom available with [15] and consists of two dielectric materials, shell and liquid. The material parameters are defined in

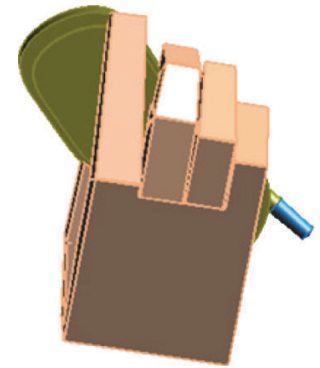

(a)

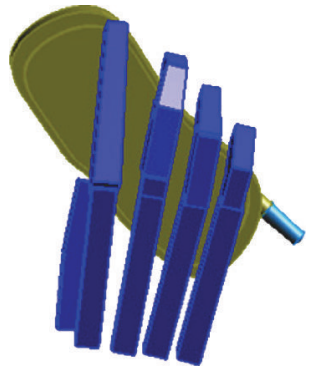

(b)
FIgure 5: The CAD representation of the proposed semirealistic hand model holding the proposed handset; (a) all hand tissues, (b) hand-bones only.

$[7,8]$, with shell and ear spacer defined in [5], at $900 \mathrm{MHz}$ and $1800 \mathrm{MHz}$.

The nonhomogeneous head phantom is a highresolution European 40-year female head (HR-EFH), derived from MRI scan [15], and is imported to the SEMCAD platform. This CAD phantom consists of 121 different slices, with slice thicknesses of $1 \mathrm{~mm}$ (ear region) and $3 \mathrm{~mm}$, and a transverse spatial resolution of $0.2 \mathrm{~mm}$. The following different 25 tissues are recognized: air, blood vessel, bones, brain/grey matter, brain/white matter, cerebellum, cerebrospinal fluid, ear (cartilage), eye-cornea, eye-lens, eyevitreous body, fat, jaw, mastoid cells (bones), mid-brain, 
TABLE 2: The generated FDTD-grid properties of both handset models in hand close to head, SAM and HR-EFH.

\begin{tabular}{lccc}
\hline Frequency & Handset & $\begin{array}{c}\text { HR-EFH-Head phantom } \\
\text { Mesh cells amount/Cheek }\end{array}$ & Mesh cells amount/Tilt \\
\hline $900 \mathrm{MHz}$ & Model no. 1 & $276 * 253 * 300=20.9484$ Mcells & $284 * 241 * 310=21.2176 \mathrm{Mcells}$ \\
$900 \mathrm{MHz}$ & Model no. 2 & $290 * 251 * 281=20.4540$ Mcells & $282 * 239 * 305=20.5564 \mathrm{Mcells}$ \\
$1800 \mathrm{MHz}$ & Model no. 1 & $268 * 244 * 288=18.8329$ Mcells & $276 * 233 * 302=19.4210 \mathrm{Mcells}$ \\
$1800 \mathrm{MHz}$ & Model no. 2 & $289 * 242 * 277=19.3728$ Mcells & $274 * 231 * 296=18.7350 \mathrm{Mcells}$ \\
\hline & & SAM-Head phantom & Mesh cells amount/Tilt \\
\hline Frequency & Handset & $208 * 135 * 234=6.57072$ Mcells & $208 * 131 * 252=6.86650 \mathrm{Mcells}$ \\
$900 \mathrm{MHz}$ & Model no. 1 & $230 * 137 * 217=6.83767$ Mcells & $230 * 131 * 223=6.71899 \mathrm{Mcells}$ \\
$900 \mathrm{MHz}$ & Model no. 2 & $200 * 127 * 230=5.84200$ Mcells & $200 * 123 * 236=5.80560 \mathrm{Mcells}$ \\
$1800 \mathrm{MHz}$ & Model no. 1 & $222 * 129 * 209=5.98534$ Mcells & $219 * 120 * 214=5.62392 \mathrm{Mcells}$ \\
$1800 \mathrm{MHz}$ & Model no. 2 & &
\end{tabular}

muscles, nasal cavity, parotid gland, spin, skull, spinal cord, spine, thalamus, tongue, and ventricles.

Head and hand tissues properties are set according to the material properties data-base in [15] and to that given in [18], where both are based on [19].

The FDTD-grid for each handset in hand close to head has a minimum spatial resolution of $0.5 \times 0.5 \times 0.5 \mathrm{~mm}^{3}$ and maximum resolution of $10 \times 10 \times 10 \mathrm{~mm}^{3}$ in the $x, y$, and $z$ directions with grading ratio of 1.2 . The absorbing boundary conditions (ABCs) are set as a perfectly matched layer (PML) mode with a very high-strength thickness [15].

Table 2 lists the amounts of mesh cells according to FDTD-grid setting for both handset models in hand close SAM and HR-EFH, at $900 \mathrm{MHz}$ and $1800 \mathrm{MHz}$.

The simulations (in all cases) assume a steady-state voltage at the 900 and $1800 \mathrm{MHz}$, with a feed point of a 50 -Ohm voltage source of 1-mm gap. A transient excitation of 12 periods is set as guarantee to achieving a steady state. The absorbing boundary conditions (ABCs) are set as a perfectly matched layer (PML) mode with a very high strength thickness [15].

In case of the handset close to head (both SAM and HR-EFH), the acoustic output referenced to earpiece is set according to IEEE standard 1528 [7]. Due to different antenna positions in both handset models, the distances between the antennas feed points and the nearest tissue voxel are different too. For the handset model no. 1 the acoustic output position is set at the origin, whereas for the handset model no. 2 the acoustic output position is set at $(x=-15$, $y=0$ and $z=-104 \mathrm{~mm}$ ). Figures 6(a) and 6(b) show both handset models close to head (SAM) at cheek position indicating the coordinate system, whereas Figure 6(c) shows the handset model no. 2 in hand close to head.

\section{EM INTERACTION BETWEEN THE HANDSET ANATENNA AND HUMAN HEAD}

The EM interaction between the handset antenna and human head is evaluated by; first, evaluating the effect of human head and hand on the handset antenna performance through computing the antenna parameters, including input return loss, gain, radiation efficiency, and total efficiency, second, evaluating the impact of antenna EM radiation on the head through computing the induced SAR and power absorption.

\subsection{Antenna performance}

Table 3 demonstrates the antenna parameters including; input return loss, gain, radiation efficiency, and total efficiency, for both handset models in all cases at $900 \mathrm{MHz}$. Table 4 lists the antenna parameters at $1800 \mathrm{MHz}$. Figure 7 shows the radiation beam pattern in $(\mathrm{V} / \mathrm{m})$ for both handset models in hand close to HR-EFH at cheek position and for both 900 and $1800 \mathrm{MHz}$ frequencies, whereas Figure 8 shows the radiation beam pattern at tilt position.

\subsection{SAR and power loss computation in head}

The impact of the electromagnetic (EM) wave irradiation on the living body is measured by evaluating the SAR which is defined as the amount of EM energy absorption in the unit mass as follow [20]:

$$
\operatorname{SAR}=\frac{\sigma_{E}}{\rho}|\mathbf{E}|^{2}
$$

where $\sigma_{E}(\mathrm{~S} / \mathrm{M})$ is the conductivity, $\mathrm{E}(\mathrm{V} / \mathrm{m})$ is the the induced electric field vector, and $\rho\left(\mathrm{kg} / \mathrm{m}^{3}\right)$ is the material density. Using SEMCAD platform, an algorithm based on SCC34/SC2/WG2 computational dosimetry, IEEE-1529 [21], the spatial peak SAR can be computed over any required mass.

The spatial-peak SAR should be evaluated in a cubical volume of the body tissues that is within $5 \%$ of the required mass [15]. The averaged peak-SAR (Spatial-peak SAR [IEEE1529]) can be specified over a cube of $1 \mathrm{~g}$ and $10 \mathrm{~g}$ mass, and normalized to a certain source power. Referred to the IEEE standard C95.1b-2004 [22] (for low-power devices, uncontrolled environment), the antenna input power is set to $0.6 \mathrm{~W}$ at $900 \mathrm{MHz}$ and $0.125 \mathrm{~W}$ at $1800 \mathrm{MHz}$, respectively, in all cases. 


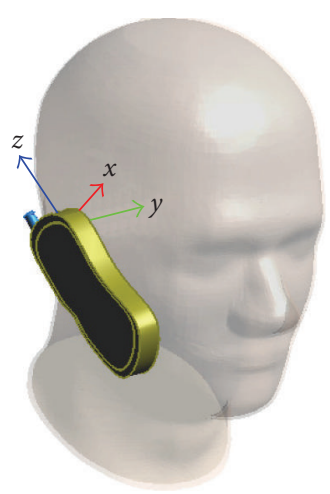

(a)

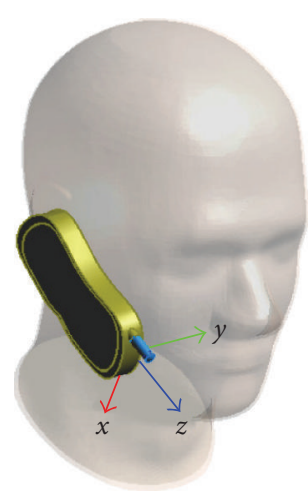

(b)

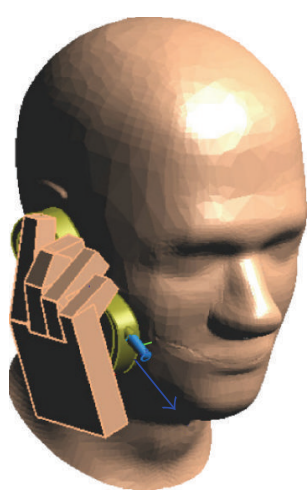

(c)

Figure 6: Coordinate system; (a) the handset model no. 1 referenced as seen from the right side of the SAM, at cheek position, (b) the handset model no. 2 referenced as seen from the right side of the SAM, at cheek position, and (c) the handset model no. 2 in hand close to SAM at cheek position.

TABLE 3: Computational results of the antenna performance parameters of both handset models at $900 \mathrm{MHz}$ in all cases.

\begin{tabular}{|c|c|c|c|c|c|c|c|c|}
\hline \multirow{4}{*}{$\begin{array}{l}\text { Frequency } \\
\text { Handset model }\end{array}$} & \multicolumn{8}{|c|}{$900 \mathrm{MHz}$} \\
\hline & \multicolumn{2}{|c|}{$\left|S_{11}\right|$ in $(\mathrm{dB})$} & \multicolumn{2}{|c|}{ Gain $(\mathrm{dBi})$} & \multicolumn{2}{|c|}{ Radiation efficiency } & \multicolumn{2}{|c|}{ Total efficiency } \\
\hline & Model & Model & Model & Model & Model & Model & Model & Model \\
\hline & no. 1 & no. 2 & no. 1 & no. 2 & no. 1 & no. 2 & no. 1 & no. 2 \\
\hline Handset in free-space & -28.4 & -21.5 & 1.72 & 1.8 & $85.76 \%$ & $86.9 \%$ & $85.63 \%$ & $86.33 \%$ \\
\hline Handset in hand only & -12.9 & -15.4 & 1.23 & -0.6 & $48.4 \%$ & $41.0 \%$ & $45.9 \%$ & $39.7 \%$ \\
\hline Handset in hand close to SAM (Cheek position) & -15.4 & -17.5 & -5.98 & -5.86 & $7.3 \%$ & $11.7 \%$ & $7.1 \%$ & $11.5 \%$ \\
\hline Handset in hand close to SAM (Tilt position) & -17.3 & -18.2 & -2.75 & -2.5 & $18.8 \%$ & $21.5 \%$ & $18.5 \%$ & $21.2 \%$ \\
\hline Handset in hand close to HR-EFH (Cheek position) & -13.8 & -24.2 & -5.5 & -3.5 & $12.8 \%$ & $17.3 \%$ & $12.3 \%$ & $17.2 \%$ \\
\hline Handset in hand close to HR-EFH (Tilt position) & -17 & -19 & -2.8 & -2.1 & $25.0 \%$ & $25.6 \%$ & $24.5 \%$ & $25.3 \%$ \\
\hline
\end{tabular}

Table 5 lists the computed peak SAR averaged over $1 \mathrm{~g}$ and $10 \mathrm{~g}$, and the absorbed power in tissues, for both handset models at both positions and at $900 \mathrm{MHz}$. Table 6 lists the computed parameters at $1800 \mathrm{MHz}$.

Figure 9 shows the sliced-distribution of the averaged peak $\mathrm{SAR}_{1 \mathrm{~g}}$ in the HR-EFH phantom exposed to EM radiation of both model no. 1 and model no. 2 antennas at cheek position and at different frequencies, whereas Figure 10 shows the sliced-distribution of the averaged peak $\mathrm{SAR}_{1 \mathrm{~g}}$ in the HR-EFH phantom exposed to EM radiation at tilt position.

\section{TOTAL ISOTROPIC SENSITIVITY}

The total isotropic sensitivity (TIS) [15] is a measure of the handset receiving performance. The TIS and TRP (total radiated power) together determine effectiveness of the handset as a piece of radio equipment, in particular the maximum range at which the handset can operate from the base station with some given level of performance [23]. The computed TIS for both handset models at $900 \mathrm{MHz}$ and $1800 \mathrm{MHz}$ are given in Tables 5 and 6.

\section{COMPUTATION ERROR}

The computation error is defined as [24]

$$
\begin{gathered}
\text { Computation error }=\left|P_{\text {in }}-\left(P_{\text {rad }}+P_{\text {abs }}+P_{\text {Loss }}\right)\right| / P_{\text {in }}, \\
P_{\text {Loss }}=P_{d}+P_{c},
\end{gathered}
$$

where $P_{\text {in }}$ is the input power, $P_{\text {rad }}$ is the radiation power, $P_{\text {abs }}$ is the absorbed power in tissues, and $P_{\text {Loss }}$ is the total power loss. $P_{\text {Loss }}$ includes the dielectric loss $\left(P_{d}\right)$ and the metallic ohmic loss $\left(P_{c}\right)$.

\section{DISCUSSION}

The results in Tables 3 and 4 reveal that presence of a head close to the handheld set of model no. 1 degrades the handset performance, significantly reducing the handset total efficiency to about $(8 \%-28 \%)$ of the total efficiency of the handset in free space. Adopting a bottom-mounted antenna, model no. 2, the total efficiency of the handset model no. 1 can be improved by $(3.3 \%-45.5 \%)$, whereas the 
TABLE 4: Computational results of the antenna performance parameters of both handset models at $1800 \mathrm{MHz}$ in all cases.

\begin{tabular}{|c|c|c|c|c|c|c|c|c|}
\hline \multirow{3}{*}{$\begin{array}{l}\text { Frequency } \\
\text { Handset model }\end{array}$} & \multicolumn{8}{|c|}{$1800 \mathrm{MHz}$} \\
\hline & \multicolumn{2}{|c|}{$\left|S_{11}\right|$ in $(\mathrm{dB})$} & \multicolumn{2}{|c|}{ Gain $(\mathrm{dBi})$} & \multicolumn{2}{|c|}{ Radiation efficiency } & \multicolumn{2}{|c|}{ Total efficiency } \\
\hline & $\begin{array}{c}\text { Model } \\
\text { no. } 1\end{array}$ & $\begin{array}{c}\text { Model } \\
\text { no. } 2\end{array}$ & $\begin{array}{c}\text { Model } \\
\text { no. } 1\end{array}$ & $\begin{array}{c}\text { Model } \\
\text { no. } 2\end{array}$ & $\begin{array}{c}\text { Model } \\
\text { no. } 1\end{array}$ & $\begin{array}{c}\text { Model } \\
\text { no. } 2\end{array}$ & $\begin{array}{c}\text { Model } \\
\text { no. } 1\end{array}$ & $\begin{array}{c}\text { Model } \\
\text { no. } 2\end{array}$ \\
\hline Handset in free-space & -31.2 & -33.4 & 3.9 & 3.8 & $95.3 \%$ & $95.8 \%$ & $95.2 \%$ & $95.7 \%$ \\
\hline Handset in hand only & -19 & -17.2 & 2.9 & 0.86 & $67.1 \%$ & $50.0 \%$ & $66.2 \%$ & $49.0 \%$ \\
\hline Handset in hand close to SAM (Cheek position) & -17.8 & -22.8 & 0.2 & -0.15 & $22.3 \%$ & $30.1 \%$ & $22 \%$ & $30.0 \%$ \\
\hline Handset in hand close to SAM (Tilt position) & -15.4 & -21 & 0.67 & 0.86 & $26.1 \%$ & $36.7 \%$ & $25.0 \%$ & $36.4 \%$ \\
\hline Handset in hand close to HR-EFH (Cheek position) & -17.1 & -21 & 1.3 & 0.2 & $25.0 \%$ & $33.4 \%$ & $24.5 \%$ & $33.1 \%$ \\
\hline Handset in hand close to HR-EFH (Tilt position) & -16.5 & -19.2 & 0.6 & 0.47 & $27.2 \%$ & $39.2 \%$ & $26.6 \%$ & $38.7 \%$ \\
\hline
\end{tabular}

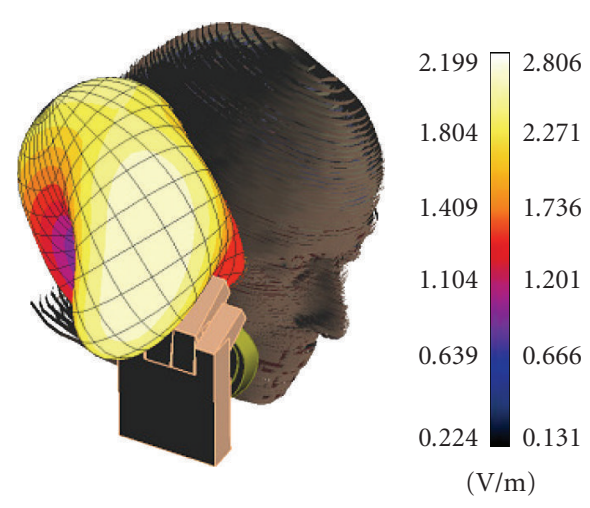

(a) Handset model no. 1 at cheek position and operating at $900 \mathrm{MHz}$
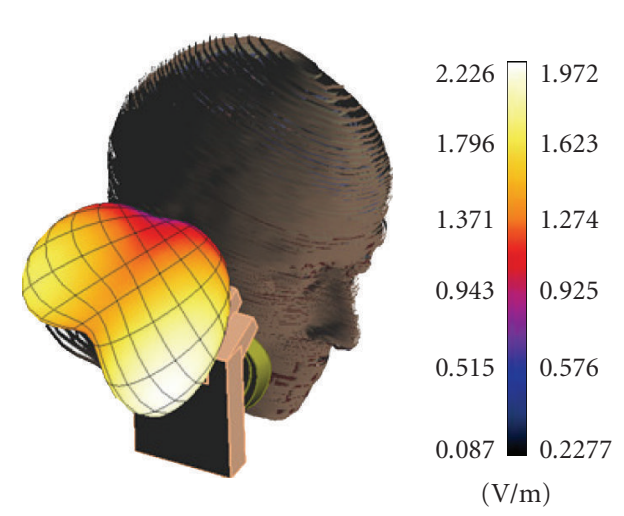

(c) Handset model no. 1 at cheek position and operating at $1800 \mathrm{MHz}$

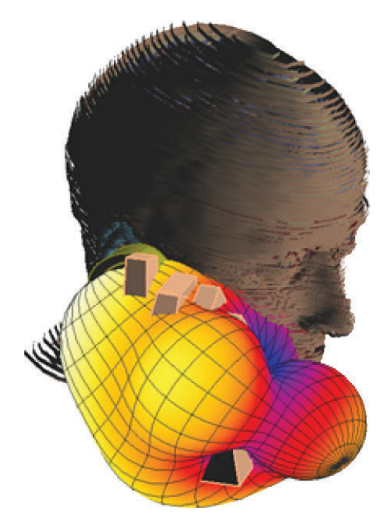

(b) Handset model no. 2 at cheek position and operating at $900 \mathrm{MHz}$

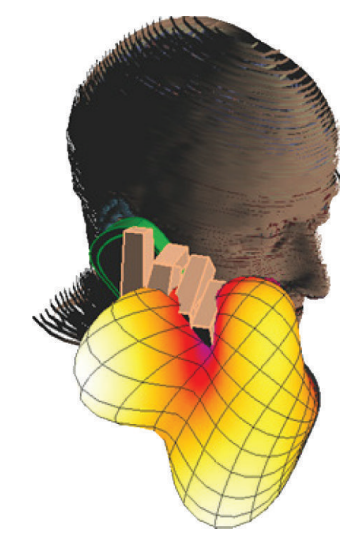

(d) Handset model no. 2 at cheek position and operating at $1800 \mathrm{MHz}$

FIgURE 7: The three-dimensional radiation pattern in $(\mathrm{V} / \mathrm{m})$ of both handset models in hand close to HR-EFH at cheek position and operating at different frequencies.

gain is reduced by $(0.19-2.15 \mathrm{dBi})$. The antennas of both handset models were matched well for all the cases.

Since the proposed handset model has an antenna in a low-noise area of the handset and well separated from the potentially noisy components, it has the potential to achieve better TIS. According to the results obtained in Tables 5 and
6, the different cases of the handset model no. 2 in hand close to head do show better TIS values, as compared with model no. 1, due to the improved total efficiency.

Moreover, Tables 5 and 6 show that the averaged peak$\mathrm{SAR}_{\mathrm{lg}}$ induced in head close to hand-held of model no. 1 can be reduced by $(28 \%-92.2 \%)$ using the proposed handset 


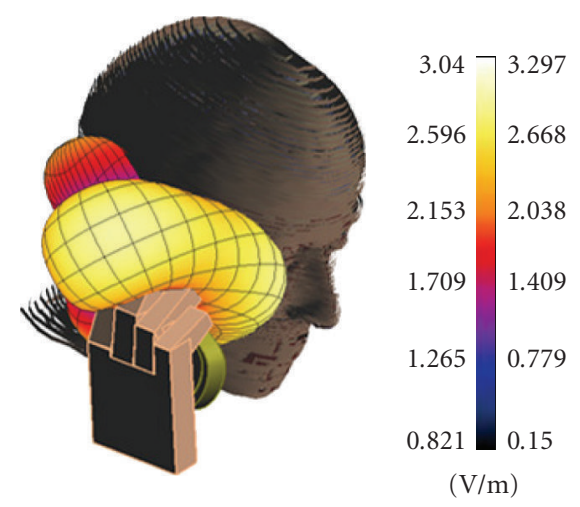

(a) Handset model no. 1 at tilt position and operating at $900 \mathrm{MHz}$
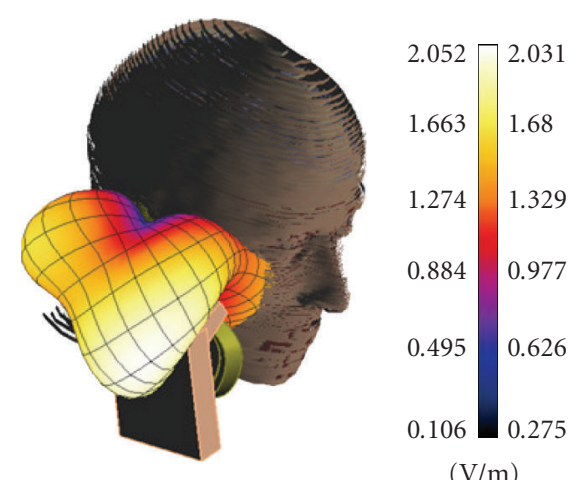

(c) Handset model no. 1 at tilt position and operating at $1800 \mathrm{MHz}$

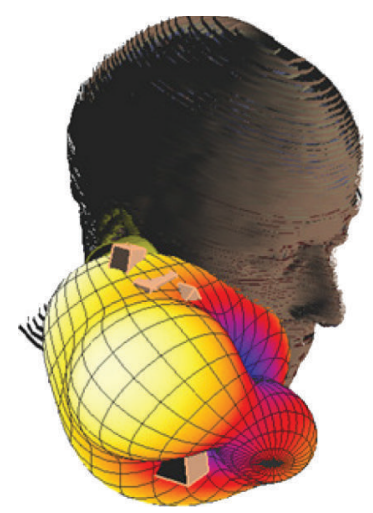

(b) Handset model no. 2 at tilt position and operating at $900 \mathrm{MHz}$

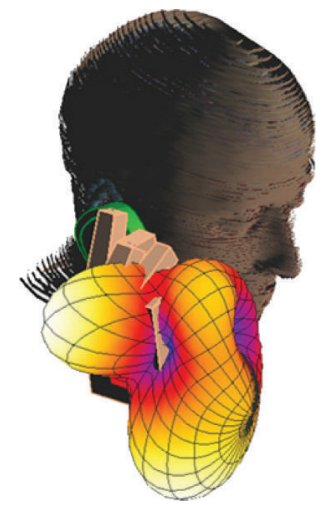

(d) Handset model no. 2 at tilt position and operating at $1800 \mathrm{MHz}$

FIGURE 8: The three-dimensional radiation pattern in $(\mathrm{V} / \mathrm{m})$ of both handset models in hand close to HR-EFH at tilt position and operating at different frequencies.

TABLE 5: The computed averaged peak-SAR (over $1 \mathrm{~g}$ and $10 \mathrm{~g}$ ) and power absorption in tissues, radiated power, total loss, total isotropic sensitivity, and computation error for both handset models in hand close to head at different positions and at $900 \mathrm{MHz}$.

\begin{tabular}{|c|c|c|c|c|c|c|c|c|}
\hline \multirow[b]{3}{*}{ Handset model } & \multicolumn{4}{|c|}{$900 \mathrm{MHz}-$ Cheek } & \multicolumn{4}{|c|}{$900 \mathrm{MHz}-$ Tilt } \\
\hline & \multicolumn{2}{|c|}{ SAM } & \multicolumn{2}{|c|}{ HR-EFH (Adult) } & \multicolumn{2}{|c|}{ SAM } & \multicolumn{2}{|c|}{ HR-EFH (Adult) } \\
\hline & Model no. 1 & Model no. 2 & Model no. 1 & Model no. 2 & Model no. 1 & Model no. 2 & Model no. 1 & Model no. 2 \\
\hline Input power $(\mathrm{mW})$ & 600 & 600 & 600 & 600 & 600 & 600 & 600 & 600 \\
\hline Peak-SAR ${ }_{1 g}(W / K g)$ in head & 4.23 & 3.34 & 2.99 & 2.72 & 1.86 & 1.34 & 4.17 & 1.09 \\
\hline Peak-SAR $_{10 \mathrm{~g}}(\mathrm{~W} / \mathrm{Kg})$ in head & 3.02 & 2.38 & 2.55 & 2.27 & 1.29 & 0.98 & 1.40 & 0.92 \\
\hline Peak-SAR $_{\lg }(\mathrm{W} / \mathrm{Kg})$ in hand & 1.44 & 2.70 & 1.69 & 2.93 & 2.02 & 3.54 & 2.18 & 3.57 \\
\hline Peak-SAR ${ }_{10 \mathrm{~g}}(\mathrm{~W} / \mathrm{Kg})$ in hand & 0.82 & 1.25 & 0.89 & 1.31 & 1.18 & 1.65 & 1.19 & 1.65 \\
\hline Radiated power (mW) & 42.60 & 69.00 & 74.00 & 103.50 & 127.20 & 110.10 & 147.00 & 152.00 \\
\hline Absorbed power in head (mW) & 335.20 & 241.40 & 312.00 & 218.50 & 206.80 & 126.60 & 206.00 & 122.00 \\
\hline Absorption rate in head (\%) & 55.87 & 40.23 & 52.00 & 36.42 & 34.47 & 21.10 & 34.33 & 20.33 \\
\hline Absorbed power in hand (mW) & 92.27 & 161.50 & 94.30 & 167.90 & 133.20 & 224.80 & 130.00 & 207.00 \\
\hline Total loss (mW) & 103.26 & 107.20 & 109.00 & 99.83 & 106.20 & 115.50 & 108.70 & 110.00 \\
\hline Total isotropic sensitivity $(\mathrm{dBm})$ & -94.5 & -96.6 & -97 & -98.4 & -99.3 & -98.7 & -99.9 & -100.1 \\
\hline Computation error $(\%)$ & 4.4 & 3.5 & 1.8 & 1.7 & 4.8 & 2.9 & 0.8 & 1.6 \\
\hline
\end{tabular}




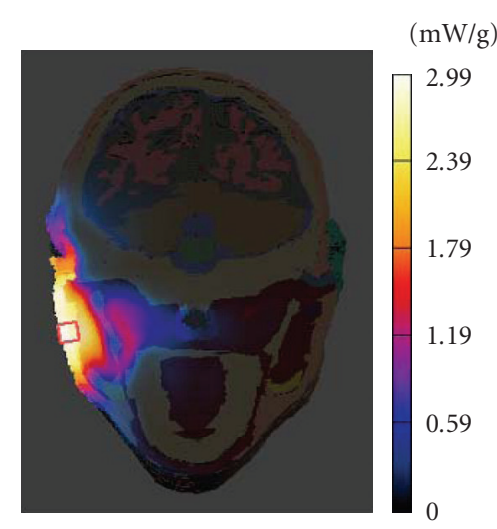

(a)

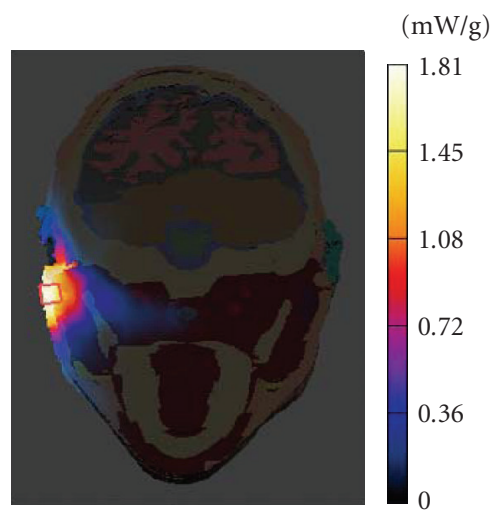

(c)

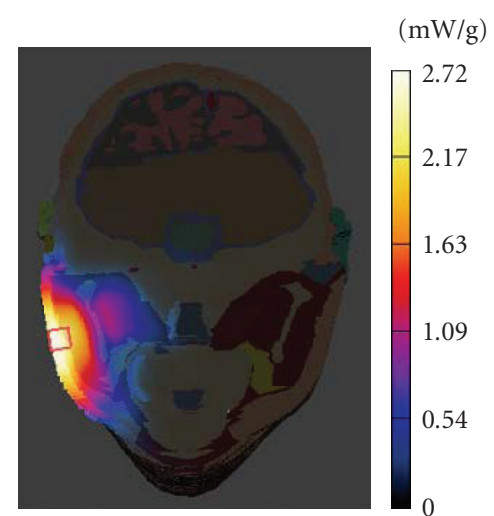

(b)

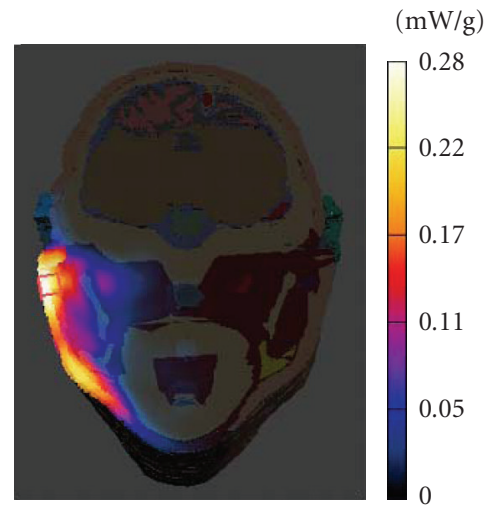

(d)

FIGURE 9: Sliced-distribution of the averaged peak $\mathrm{SAR}_{1 \mathrm{~g}}$ in the $y z$-plane of the HR-EFH phantom in cases of handset models at cheek position. The antenna input powers are $0.6 \mathrm{~W}$ and $0.125 \mathrm{~W}$ for the frequencies $900 \mathrm{MHz}$ and $1800 \mathrm{MHz}$, respectively. (a) Model no. 1 at 900 MHz, (b) Model no. 2 at $900 \mathrm{MHz}$, (c) Model no. 1 at $1800 \mathrm{MHz}$, (d) Model no. 2 at $1800 \mathrm{MHz}$.

TABLE 6: The computed averaged peak-SAR (over $1 \mathrm{~g}$ and $10 \mathrm{~g}$ ) and power absorption in tissues, radiated power, total loss, total isotropic sensitivity, and computation error for both handset models in hand close to head at different positions and at $1800 \mathrm{MHz}$.

\begin{tabular}{|c|c|c|c|c|c|c|c|c|}
\hline \multirow[b]{3}{*}{ Handset model } & \multicolumn{4}{|c|}{$1800 \mathrm{MHz}-$ Cheek } & \multicolumn{4}{|c|}{$1800 \mathrm{MHz}-$ Tilt } \\
\hline & \multicolumn{2}{|c|}{ SAM } & \multicolumn{2}{|c|}{ HR-EFH (Adult) } & \multicolumn{2}{|c|}{ SAM } & \multicolumn{2}{|c|}{ HR-EFH (Adult) } \\
\hline & Model no. 1 & Model no. 2 & Model no. 1 & Model no. 2 & Model no. 1 & Model no. 2 & Model no. 1 & Model no. 2 \\
\hline Input power $(\mathrm{mW})$ & 125 & 125 & 125 & 125 & 125 & 125 & 125 & 125 \\
\hline Peak-SAR $_{1 \mathrm{~g}}(\mathrm{~W} / \mathrm{Kg})$ in head & 1.38 & 0.47 & 1.81 & 0.28 & 1.29 & 0.14 & 1.93 & 0.15 \\
\hline Peak-SAR ${ }_{10 g}(W / K g)$ in head & 0.87 & 0.30 & 1.13 & 0.18 & 0.82 & 0.08 & 0.97 & 0.10 \\
\hline Peak-SAR $_{1 \mathrm{~g}}(\mathrm{~W} / \mathrm{Kg})$ in hand & 0.73 & 1.22 & 0.73 & 1.25 & 0.80 & 1.47 & 0.80 & 1.43 \\
\hline Peak-SAR $_{10 g}(\mathrm{~W} / \mathrm{Kg})$ in hand & 0.42 & 0.64 & 0.42 & 0.66 & 0.45 & 0.71 & 0.46 & 0.73 \\
\hline Radiated power (mW) & 27.50 & 37.45 & 30.65 & 41.40 & 31.67 & 45.55 & 33.34 & 48.40 \\
\hline Absorbed power in head (mW) & 59.50 & 25.46 & 61.00 & 21.50 & 51.18 & 12.39 & 54.20 & 12.16 \\
\hline Absorption rate in head (\%) & 47.60 & 20.37 & 48.80 & 17.20 & 40.94 & 9.91 & 43.36 & 9.73 \\
\hline Absorbed power in hand $(\mathrm{mW})$ & 24.40 & 51.28 & 24.97 & 52.30 & 29.00 & 55.20 & 29.55 & 55.57 \\
\hline Total loss (mW) & 7.66 & 7.21 & 7.43 & 7.80 & 7.66 & 7.84 & 7.19 & 7.65 \\
\hline Total isotropic sensitivity ( $\mathrm{dBm}$ ) & -98.8 & -100.8 & -100 & -101.3 & -100.1 & -101.6 & -100.3 & -101.9 \\
\hline Computation error $(\%)$ & 4.4 & 3.8 & 1.4 & 1.5 & 4.4 & 3.2 & 0.6 & 1.0 \\
\hline
\end{tabular}

model no. 2, and the power absorbed in head can also be reduced by $(27.9 \%-77.5 \%)$. The computation errors are less than $2 \%$ for all cases in presence of HR-EFH, whereas for the cases of SAM presence they are $(1.4 \%-4.4 \%)$.

The differences in the induced SAR and absorption power values in both SAM and HR-EFH phantoms are due to their different masses, volumes, and densities distribution. According to simulation results, HR-EFH mass is approximately $4.71 \mathrm{~kg}$ and the volume is approximately $4118 \mathrm{~cm}^{3}$, while the SAM mass is approximately $6.024 \mathrm{~kg}$ (considering a homogeneous density of $1000 \mathrm{~kg} / \mathrm{m}^{3}$ ) and the volume is approximately $6043 \mathrm{~cm}^{3}$. 


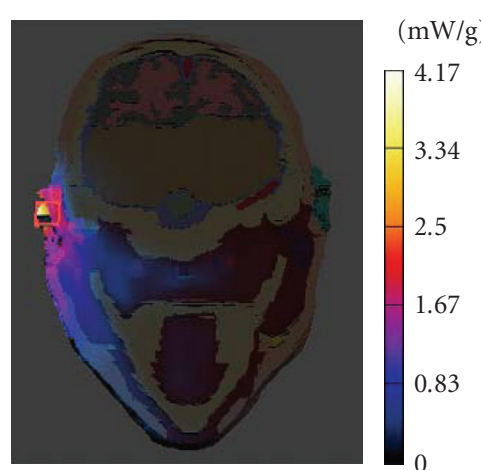

(a)

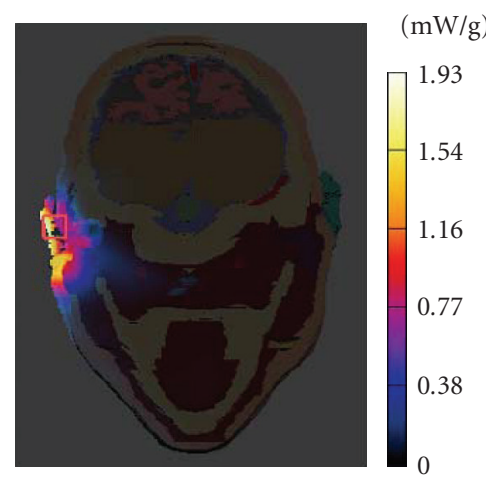

(c)

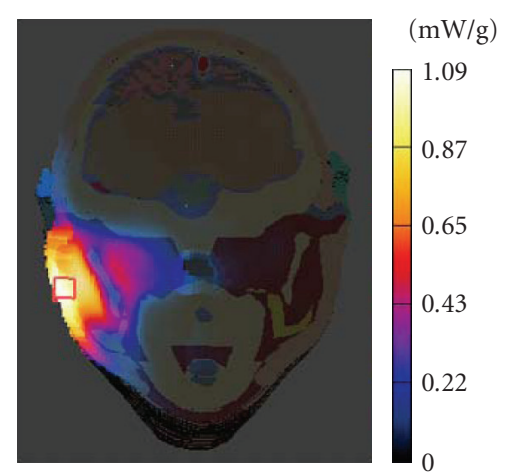

(b)

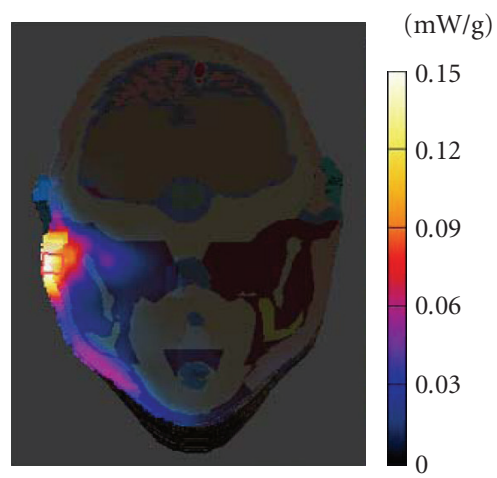

(d)

FIGURE 10: Sliced-distribution of the averaged peak $\mathrm{SAR}_{1 \mathrm{~g}}$ in the $y z$-plane of the HR-EFH phantom in cases of handset models at tilt position. The antenna input powers are $0.6 \mathrm{~W}$ and $0.125 \mathrm{~W}$ for the frequencies $900 \mathrm{MHz}$ and $1800 \mathrm{MHz}$, respectively. (a) Model no. 1 at $900 \mathrm{MHz}$, (b) Model no. 2 at $900 \mathrm{MHz}$, (c) Model no. 1 at $1800 \mathrm{MHz}$, (d) Model no. 2 at $1800 \mathrm{MHz}$.

The proposed human-hand model mass is approximately $0.248 \mathrm{~kg}$ and its volume is approximately $186 \mathrm{~cm}^{3}$.

All computations are performed on a $2.0-\mathrm{GHz}$ Intel centrino Laptop machine (Dell, inspiron-630 m) with 2 GB memory (dual-channel technology), and operating under MS Windows-vista. The runtime and memory requirements depend on the simulation space. Less memory and runtime are required for the handset simulation in free space, whereas, more memory and runtime are required for the handset in hand close to head. The machine-memory is enough to achieve all simulations with the mesh cells amounts listed in Table 2 . The runtimes are about 1-10 hours.

\section{CONCLUSION}

A cellular handset with a keypad over the screen and a bottom-mounted antenna has been proposed and numerically modeled, with the most handset components, using an FDTD-based SEMCAD platform. The proposed handset model is based on the commercially available model with a top-mounted external antenna. Both homogeneous and nonhomogeneous head phantoms have been used with a semirealistic hand design to simulate the handset in hand close to head. The simulation results showed a significant improvement in the antenna performance with the proposed handset model in hand close to head, as compared with the handset of top-mounted antenna. Also, using this proposed handset, a significant reduction in the induced SAR and power absorbed in head has been achieved.

\section{REFERENCES}

[1] N. K. Kouveliotis, S. C. Pabagiotou, P. K. Varlamos, and C. N. Capsalis, "Theoretical approach of the interaction between a human head model and a mobile handset helical antenna using numerical methods," Progress in Electromagnetics Research, vol. 65, pp. 309-327, 2006.

[2] K. Sulonen and P. Vainikainen, "Performance of mobile phone antennas including effect of environment using two methods," IEEE Transaction on Instrumentation and Measurement, vol. 52, no. 6, pp. 1859-1864, 2003.

[3] J. Krogerus, C. Icheln, and P. Vainikainen, "Dependence of mean effective gain of mobile terminal antennas on side of head," in Proceedings of the 35th European Microwave Conference, pp. 467-470, Paris, France, October 2005.

[4] H. Haider, H. Garn, G. Neubauer, and G. Schmidt, "Investigation of mobile phone antennas with regard to power efficiency and radiation safety," in Proceedings of the Workshop on Mobile Terminal and Human Body Interaction, Bergen, Norway, April 2000.

[5] B. B. Beard, W. Kainz, T. Onishi, et al., "Comparisons of computed mobile phone induced SAR in the SAM phantom to that in anatomically correct models of the human head," IEEE 
Transaction on Electromagnetic Compatibility, vol. 48, no. 2, pp. 397-407, 2006.

[6] N. Chavannes, R. Tay, N. Nikoloski, and N. Kuster, "Suitability of FDTD-based TCAD tools for RF design of mobile phones," IEEE Antennas and Propagation Magazine, vol. 45, no. 6, pp. 52-66, 2003.

[7] "Recommended Practice for Determining the Peak SpatialAverage Specific Absorption Rate (SAR) in the Human Head from Wireless Communications Devices-Measurement Techniques," IEEE Standard-1528, December 2003.

[8] "Human Exposure to Radio Frequency Fields from HandHeld and Body-Mounted Wireless Communication DevicesHuman Models, Instrumentation, and Procedures-Part 1: Procedure to Determine the Specific Absorption Rate (SAR) for Hand-Held Devices Used in Close Proximity to the Ear (Frequency Range of 300 MHz to 3 GHz)," IEC 62209-1, 2005.

[9] "Basic Standard for the Measurement of Specific Absorption Rate Related to Exposure to Electromagnetic Fields from Mobile Phones (300 MHz-3 GHz)," European Committee for Electrical Standardization (CENELEC), EN 50361, 2001.

[10] "Specific Absorption Rate (SAR) Estimation for Cellular Phone," Association of Radio Industries and Businesses (ARIB) STD-T56, 2002.

[11] "Federal Communications Commission (FCC) Evaluating Compliance with FCC Guidelines for Human Exposure to Radio Frequency Electromagnetic Fields," Supplement C to OET Bulletin 65 (Edition 9701), Washington, DC: FCC, 1997.

[12] J. Wang and O. Fujiwara, "Comparison and evaluation electromagnetic absorption characteristics in realistic human head models of adult and children for $900 \mathrm{MHz}$ mobile telephones," IEEE Transaction on Microwave Theory and Techniques, vol. 51, no. 3, pp. 966-971, 2003.

[13] J. Wang, O. Fujiwara, and S. Watanabe, "Approximation of aging effect on dielectric tissue properties for SAR assessment of mobile telephones," IEEE Transaction on Electromagnetic Compatibility, vol. 48, no. 2, pp. 408-413, 2006.

[14] M. Burkhardt, "Contributions toward uncertainty assessments and error minimization of FDTD simulations involving complex dielectric bodies," Ph.D. dissertation, Diss. ETH Nr.13176, Zurich, Switzerland, 1999.

[15] SEMCAD, Reference Manual for the SEMCAD Simulation Platform for Electromagnetic Compatibility, Antenna Design and Dosimetry, SPEAG-Schmid \& Partner Engineering AG, http://www.semcad.com/.

[16] http://www.linuxdevices.com/news/NS7002110505.html.

[17] K. Ogawa and T. Uwano, "A diversity antenna for very small $800 \mathrm{MHz}$ band portable telephones," IEEE Transaction on Antenna and Propagation, vol. 42, no. 9, pp. 1342-1345, 1994.

[18] Dielectric Properties of Body Tissue in the frequency range $10 \mathrm{~Hz}-100 \mathrm{GHz}$ Italian National Research Council, Institute for Applied Physics, Florence, Italy, http://niremf.ifac.cnr.it/ tissprop/.

[19] C. Gabriel, "Compilation of the dielectric properties of body tissues at RF and microwave frequencies," Tech. Rep. N.AL/OE-TR-1996-0037, Occupational and Environmental Health Directorate, Radiofrequency Radiation Division, Brooks Air Force Base, San Antonio, Tex, USA, June 1996.

[20] H. Arai, Measurement of Mobile Antenna Systems, Artech House, Norwood, Mass, USA, 2001.

[21] "Recommended Practice for Determining the Peak SpatialAverage Specific Absorption Rate (SAR) associated with the use of wireless handsets - computational techniques," draft standard, IEEE-1529.
[22] "IEEE Standard for safety Levels with respect to human exposure to radio frequency electromagnetic fields, $3 \mathrm{kHz}$ to $300 \mathrm{GHz}$, Amendment 2: Specific Absorption Rate (SAR) Limits for the Pinna," IEEE Standard C95.1b-2004, December 2004.

[23] Z. N. Chen, Antennas for Portable Devices, John Wiely \& Sons, Hoboken, NJ, USA, 2007.

[24] L. C. Kuo, Y. C. Kan, and H. R. Chuang, "Analysis of a 900/1800 MHz dual-band gap loop antenna on a handset with proximate head and hand model," Journal of Electromagnetic Waves and Applications, vol. 21, no. 1, pp. 107-122, 2007. 

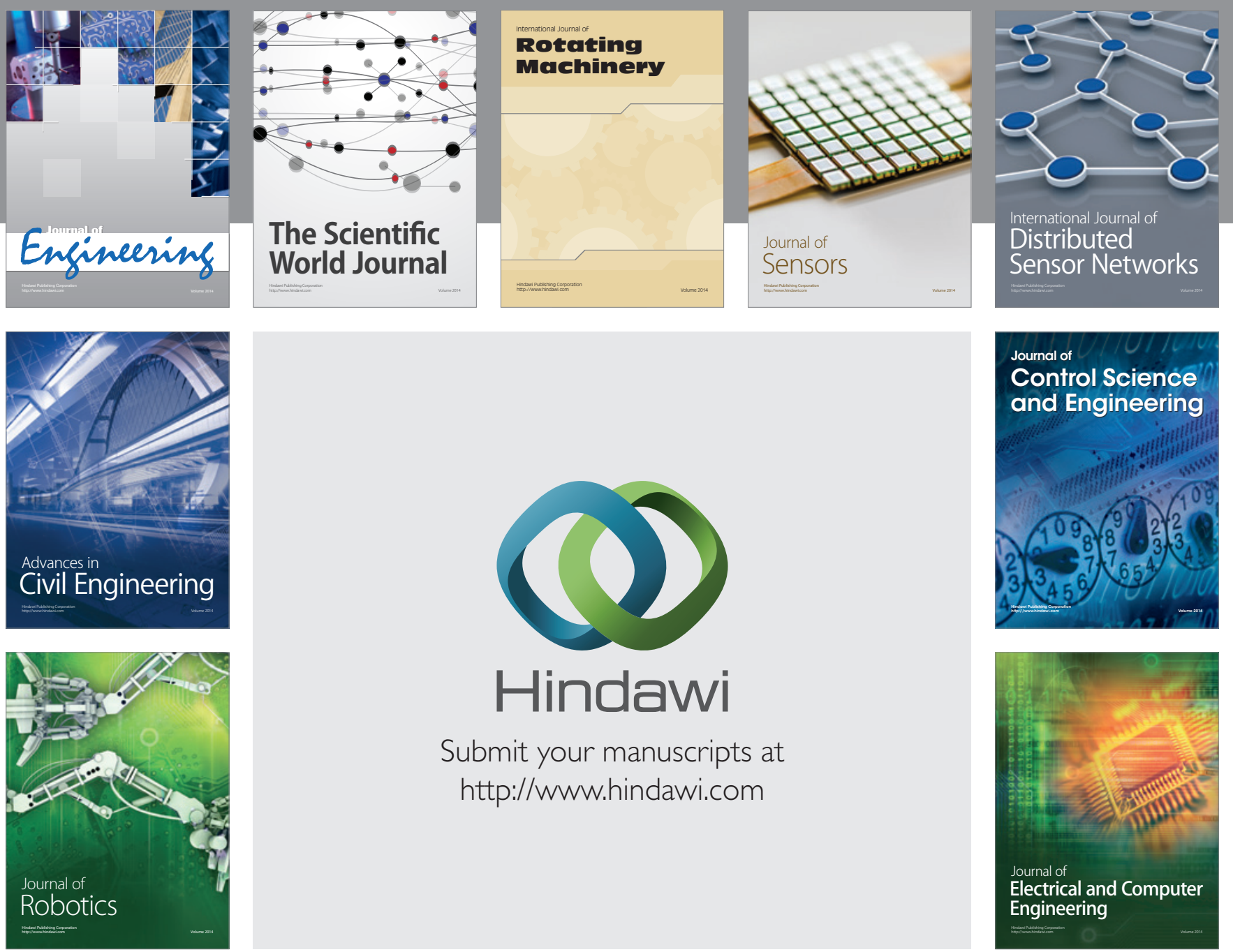

Submit your manuscripts at

http://www.hindawi.com
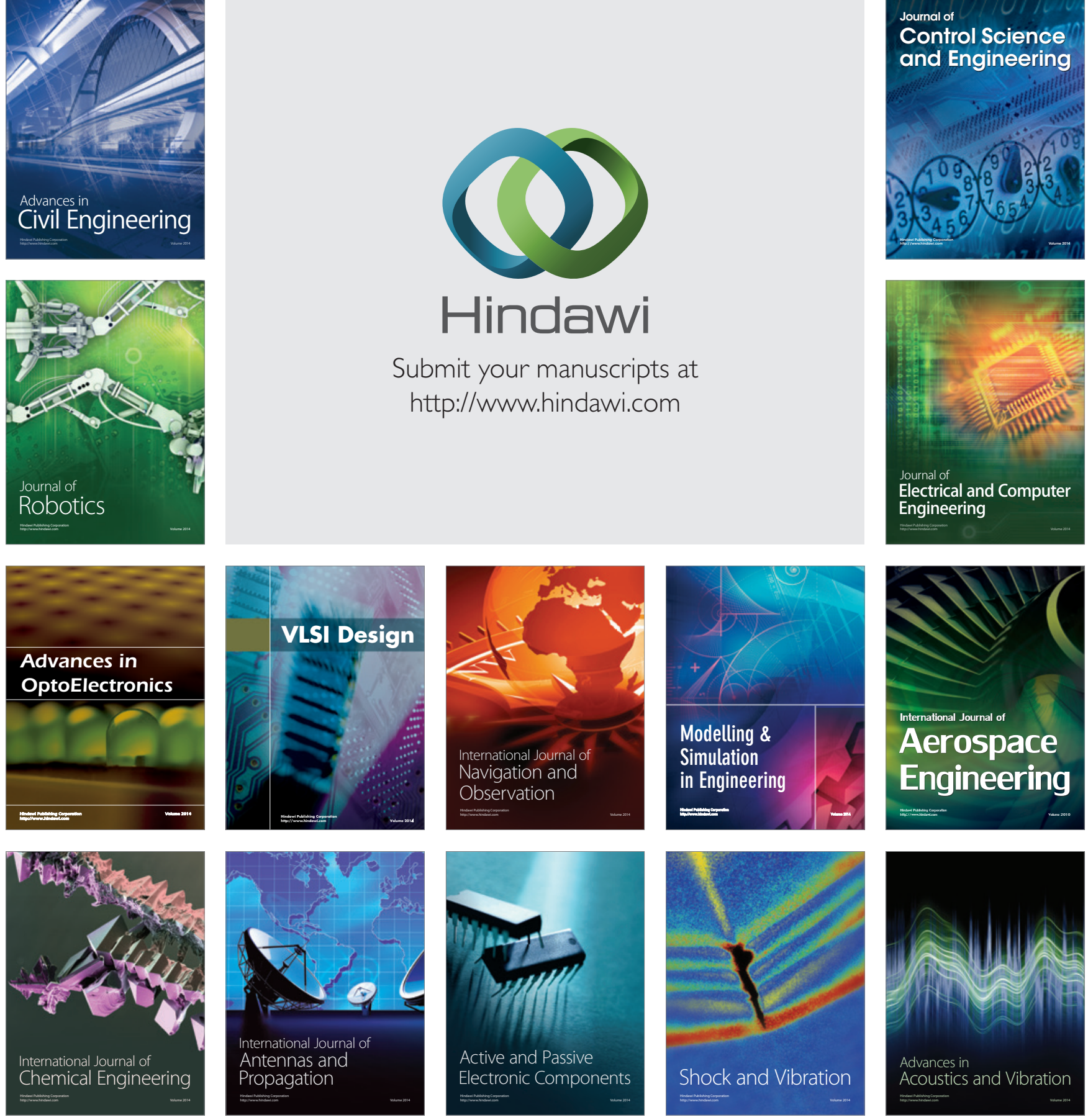